Original Research

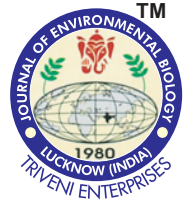

DOI : http://doi.org/10.22438/jeb/38/5/MS-141

\title{
Genetic diversity of sugar beet genotypes evaluated by microsatellite DNA markers
}

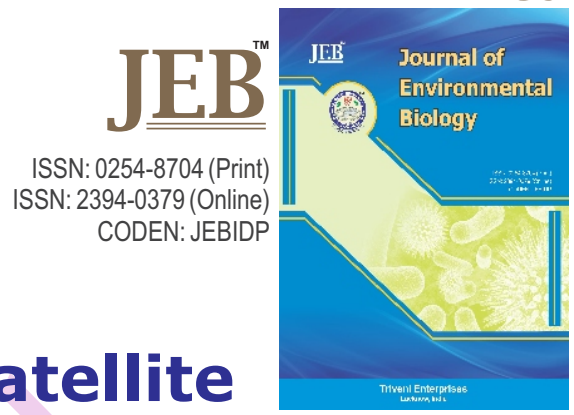

\section{Authors Info}

\section{S. Srivastava*, A. D. Pathak,} R. Kumar and B.B. Joshi

Division of Crop Improvement, ICAR-Indian Institute of Sugarcane Research, Lucknow-226 002, India

${ }^{*}$ Corresponding Author Email : sangeeta_iisr@yahoo.co.in

Key words

Beta vulgaris,

DNA markers,

Genetic variation,

Genotypes,

Microsatellite

\section{Publication Info}

Paper received : 19.08 .2015

Revised received : 02.11.2016

Re-revised received : 28.11 .2016

Accepted : 15.02.2017

\section{Abstract}

Aim: Identification of diverse sugar beet (Beta vulgaris L.) genotypes is essential for using them as parents in sugar beet improvement programme of India. Hence, genetic variation and diversity of elite sugar beet germplasm collection was analysed using microsatellite markers.

Methodology: Genomic DNA of thirteen genotypes was amplified using 14 microsatellite primers containing dinucleotide to compound repeat motifs. Amplified bands were scored on gel, transformed into a binary character matrix and analyzed through NTSYS software for clustering in heterotic groups.

Results: A total of 243 amplicons were resolved and grouped into 88 alleles of distinct molecular weight ranging from 124 to $1222 \mathrm{bp}$ with an average of 17.36 amplicons/primer, 4 to10 alleles/SSR locus and moderate to high PIC ranging from 0.625-0.851. Similarity coefficients ( S M ) ba sed on the presence/absence of alleles ranged from 0.47 to 0.89 (mean value of 0.65). UPGMA dendrogram based on SM, grouped these genotypes in two major taxonomical groups with five clusters having one, four, three, three and two genotypes each. Clustering pattern of UPGMA matched with the $2 \mathrm{D}$ and $3 \mathrm{D}$ scatter plots of MDS and PCA. The highly significant cophenetic coefficient of $r$ $=0.96$ proved that these SSR markers efficiently analyzed the genetic relationships of sugar beet genotypes.

Interpretation: Microsatellite markers can be used as a potential cost effective method for exploring molecular genetic diversity in sugar beet in order to obtain new genetic combinations.
Identification of genetically diverse genotypes

Ny
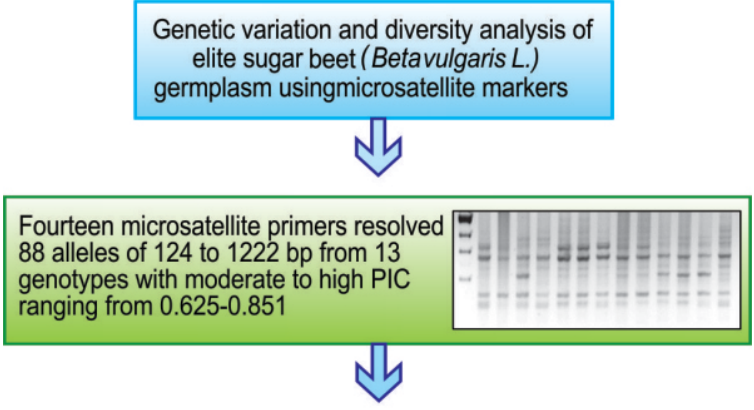

Genetic similaritycoefficients (SM) rangedfrom 0.47 to 0.89 and grouped the genotypesin two major taxonomical groups with five clusters through UPGMA having 1, 4, 3, 3 and 2 genotypes each

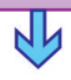

Further Grouping of genotypes with2D and 3D plots of MDS and PCAmatched with the UPGMA clustering

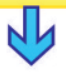

Highly significant cophenetic coefficient $(r=0.96)$ proved that these SSR markers analyzed the genetic relationships of sugar beetgenotypesefficiently

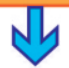

Microsatellitescan be used as a potential cost effective tool for exploring molecular diversity in sugar beet 


\section{Introduction}

Sugar beet (Beta vulgaris subsp. vulgaris), an important sugar crop of temperate climate zone belongs to family Chenopodiaceae and contributes towards one third of the global sugar production approximately (Draycott, 2006). In India, it is a supplementary sugar crop of short-duration with high sugar content bridging the gap between actual and projected sugar production, along with the production of valuable byproducts (Pathak et al., 2014). Cultivated varieties of sugar beet have a narrow genetic base and are either diploid $(2 n=18)$ or triploid $(2 n$ $=27$ ) hybrids resulting from an inbred monogerm. The genetic diversity of sugar beet has been ascertained in past using morphological traits, isozymes and molecular marker systems. DNA marker systems such as RFLP (Restriction Fragment Length Polymorphism), RAPD (Random Amplified Polymorphic DNA) and AFLP (Amplified Fragment Length Polymorphism) were used in sugar beet in early and mid-90s (Jung et al., 1993; Barzen et al., 1995; Schondelmaier et al., 1996). Linkage maps and QTL mapping based on RAPD, AFLP, SNP (Single Nucleotide Polymorphisms) and microsatellites / SSR (Simple Sequence Repeat) markers were also attempted (Möhring et al., 2005; Grimmer et al., 2007; Rae et al., 2000; Schneider et al., 2007). CAPS marker (Cleaved Amplified Polymorphic Sequences) associated with root-knot nematode resistance in sugar beet (Weiland and Yu, 2003), mitochondrial DNA and SSR polymorphism for genetic diversity (Virad et al., 2002), comparison of marker systems viz. DArT (Diversity Array-Technology), SSRs and SNPs (Simko et al., 2012), isozymes, ISSR (Inter Simple Sequence Repeats) and RAPD (Srivastava et al., 2007) and microsatellites isolated from genomic libraries and ESTs (Laurent et al., 2007) are some other instances of molecular marker research in sugar beet. Amongst these, microsatellites have always been a matter of choice as they are hyper variable, multiallelic, codominantly inherited, reproducible and abundant, besides being the most appropriate tool to describe genetic diversity at DNA level (Kalia et al., 2011). Several sugar beet specific polymorphic genomic and EST-SSR markers (Mörchen et al., 1996; McGrath et al., 2007; Richards et al., 2004; Smulders et al., 2010) and transcript-based SSR markers (Fugate et al., 2014) have been developed. Despite the availability of such vast literature on the development of SSR markers in sugar beet, their actual use in genetic diversity analysis of elite sugar beet germplasm is limited. Hence, the current study aimed to unravel genetic variation and diversity of elite sugar beet genotypes available in germplasm collection using microsatellite markers in order to identify heterotic breeding groups for further use as parents in sugar beet improvement programme of India.

\section{Materials and Methods}

DNA isolation and SSR amplification : Thirteen sugar beet genotypes viz. IN-4, IN-5, IN-6, IN-7, IN-8, IN-9, IN-10, IN-11 and R-06 (from the sugar beet germplasm collection at IISR, Lucknow), and LS-6, LKC-11, LKS-10 and IISR Comp -1 (developed at IISR, Lucknow) were used as experimental material. Genomic DNA was isolated from approximately $5 \mathrm{~g}$ of freshly harvested leaf tissue from ten randomly selected plants of each genotype using modified CTAB method (Srivastava and Gupta, 2001). The purified DNA was quantified in $0.8 \%$ (w/v) agarose gels by comparison with known quantities of the lambda phage DNA and stored at $-20^{\circ} \mathrm{C}$. Fourteen microsatellite primer pairs (table 1) retrieved from the literature were used to amplify the gDNA of sugar beet genotypes. Amplification reactions were carried out in PTC 200 (MJ Research ${ }^{\mathrm{TM}}$ Inc., Waltham, USA), in medium containing 1 X PCR buffer, $1.25 \mathrm{mM}$ d NTPs, $2 \mu \mathrm{M}$ primer reverse \& forward each, $4 \mathrm{mM} \mathrm{MgCl}$, 1 Unit Taq polymerase and $10 \mathrm{ng}$ template DNA. Each amplification experiment was performed thrice. $25 \mu$ l of each amplified product was run on $3 \%$ agarose gels (super MT4 agarose) in 1X TAE buffer in Bio Rad Sub Cell GT electrophoresis unit and stained by $0.5 \mu \mathrm{g} / \mathrm{ml}$ of ethidium bromide (EtBr). Electrophoresed samples were photographed using Alphalmager ${ }^{\mathrm{TM}}$ gel documentation system (Protein Simple, San Jose, California, USA).

Data analysis : Data on reproducible polymorphic bands were scored for the presence or absence in each sample and positions of unequivocally scorable bands were transformed into a binary character matrix (" 1 " for the presence and " 0 " for the absence of a band at a particular position). Both monomorphic and polymorphic bands across the genotypes were considered for calculation. In order to characterize the capacity of each primer to detect polymorphic loci among the genotypes, the polymorphism information content (PIC) values of all the primers were calculated by the following formula :

$$
\begin{aligned}
& \mathrm{PIC}=1-\sum \mathrm{pi}_{2} \\
& \text { where, } \mathrm{pi} \text { is the frequency of the } \mathrm{i}^{\text {th }} \text { allele. }
\end{aligned}
$$

The pooled and averaged scores of replicated data for each genotype were used to estimate the genetic similarity matrix through SM similarity coefficient. The similarity matrices generated so were used to perform cluster analysis by the Unweighted Pair Group Method with Arithmetic Mean clustering (UPGMA) method (Sneath and Sokal, 1973) following the Sequential Agglomerative Hierarchical Nested (SAHN) cluster analysis module. The goodness-of-fit of the dendrogram to the original genetic symmetry/dissymmetry matrix was calculated by computing the co-phenetic value (rcoph) using $\mathrm{COPH}$ (cophenetic) and MXCOMP (matrix comparison) modules. In order to complement the information provided by cluster analysis, multidimensional scaling (MDS) was done to create $2 \mathrm{D}$ and $3 \mathrm{D}$ scatter plots. Further, the Principal Component Analysis (PCA) was carried out to show multiple dimensions of distribution of genotypes in a scatter-plot. All the statistical analyses were done by software NTSYSpc version $2.11 \mathrm{~V}$ (Exeter software, N.Y.; Rohlf, 2000).

\section{Results and Discussion}

Distinct multiple band profiles were produced by fourteen SSR primers for thirteen sugar beet varieties (Fig. 1). These 


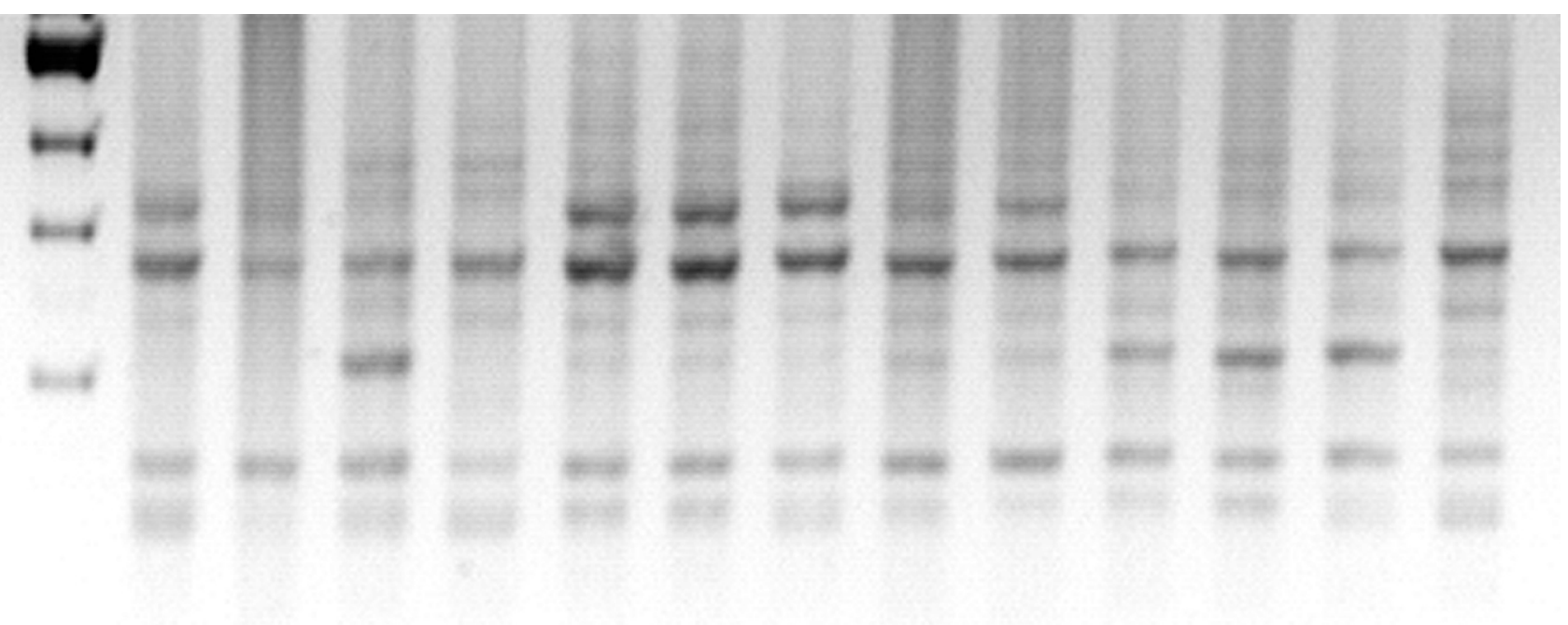

Fig. 1 : PCR amplification profile of sugar beet genotypes with SSR primer pair SB-09

Table 1 : A description of core motifs, number of alleles produced, their range of molecular weight and PIC values of sugar beet microsatellite markers used in the present study

\begin{tabular}{lllll}
\hline Primer name* & Core motif & Number of alleles & Molecular wt. (range) & PIC value \\
\hline SB-04 & $(\mathrm{GGA})_{4}$ & 6 & $133-408$ & 0.833 \\
SB-06 & $(\mathrm{CTT})_{6}$ & 5 & $175-910$ & 0.8 \\
SB-07 & $(\mathrm{TC})_{10}$ & 5 & $150-576$ & 0.67 \\
SB-09 & $(\mathrm{CAT})_{7}$ & 8 & $139-457$ & 0.842 \\
SB-10 & $(\mathrm{GAT})_{6}$ & 7 & $124-348$ & 0.698 \\
SB-11 & $(\mathrm{GA})_{8}$ & 4 & $303-687$ & 0.684 \\
SB-13 & $(\mathrm{GAT})_{9}$ & 4 & $140-294$ & 0.625 \\
SB-15 & $(\mathrm{CT})_{8}$ & $133-732$ & 0.851 \\
SB-GCC1 & $(\mathrm{GGC})_{6}$ & 5 & $160-242$ & 0.84 \\
SB-GAA1 & $\mathrm{CAA}(\mathrm{GAA})_{3} \mathrm{~T}(\mathrm{GAAAGAA})_{2}(\mathrm{GA})_{2}$ & 5 & $142-394$ & 0.684 \\
SB-GTT1 & $(\mathrm{C})_{5} \mathrm{AAC}(\mathrm{CCA})_{5}$ & 10 & $134-807$ & 0.812 \\
SB-Bvm3 & $(\mathrm{CT})_{15} \mathrm{CC}(\mathrm{T})_{10}$ & 7 & $143-449$ & 0.702 \\
SB-CT4 & $(\mathrm{CT})_{11}$ & 8 & $169-1222$ & 0.816 \\
SB-CAA1 & $(\mathrm{CAT})_{4}(\mathrm{CAA})_{14}$ & 6 & $178-430$ & 0.837 \\
\hline
\end{tabular}

*Source : Richards et al. (2004) and Viard et al. (2002)

primers were flanking sequences of dinucleotide to compound repeat motifs of mono to hexa-nucleotide repeats (Table 1). All the primers showed complete parsimony and gave multiallelic response. An average of 17.36 amplicons per primer and 13 to 23 amplicons per genotype were obtained. A total of 243 amplicons with molecular weights ranging from 124 to $1222 \mathrm{bp}$ were detected, which were grouped into 88 SSR loci of distinct size having sufficient polymorphism. The number of alleles per locus varied from 4 (primer SB-11 and SB-13) to 10 (primer SB-GTT1), with a mean of 6.29 alleles per locus (Table 1). This observation is in good agreement with Abbasi et al. (2014) and Richards et al. (2004) who found 2 to 10 and 2 to 11 alleles respectively for amplification of SSR markers in sugar beet. Desplanque et al. (1999) and Viard et al. (2002) found up to 10 alleles per locus in wild sugar beet. All the primers showed complete parsimony and were useful for diversity purpose. Each of the SSR loci displayed high level of heterozygosity and moderate to high PIC values ranging from 0.625 (primer SB-13) to 0.851 (primer SB-15). PIC had a mean value of 0.76 demonstrating the good discriminatory power and highly informative nature of these microsatellite primers as well as diversity of the genotypes used (Table 1). The primers SB-11, SB-09, SB-GCC1, SB-CAA1 and SB-04 were particularly informative for diversity purpose as they generated high PIC values ranging from 0.833 to 0.851 .

The presence vs. absence data of 88 loci generated through fourteen primer pairs across thirteen sugar beet varieties (Beta vulgaris L.) was subjected to simple matching (SM) similarity 


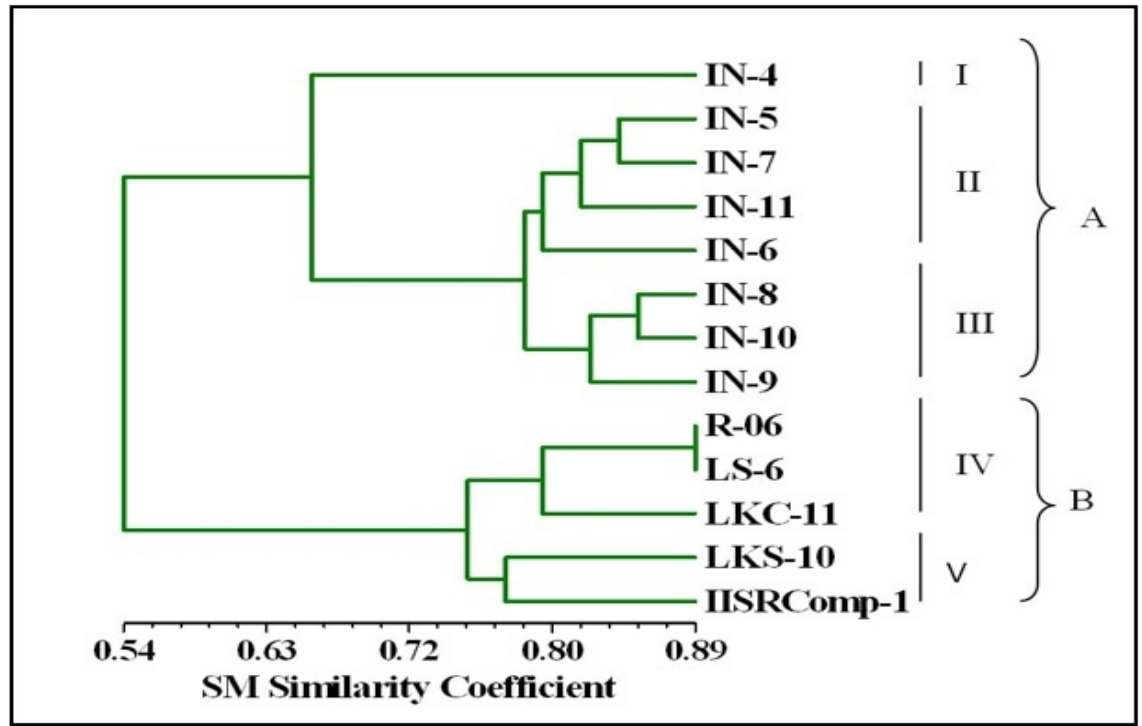

Fig. 2 : UPGMA clustering of sugar beet genotypes based on similarity coefficients. Two main taxonomic groups (A and B) and five sub clusters were identified. The scale indicates similarity levels
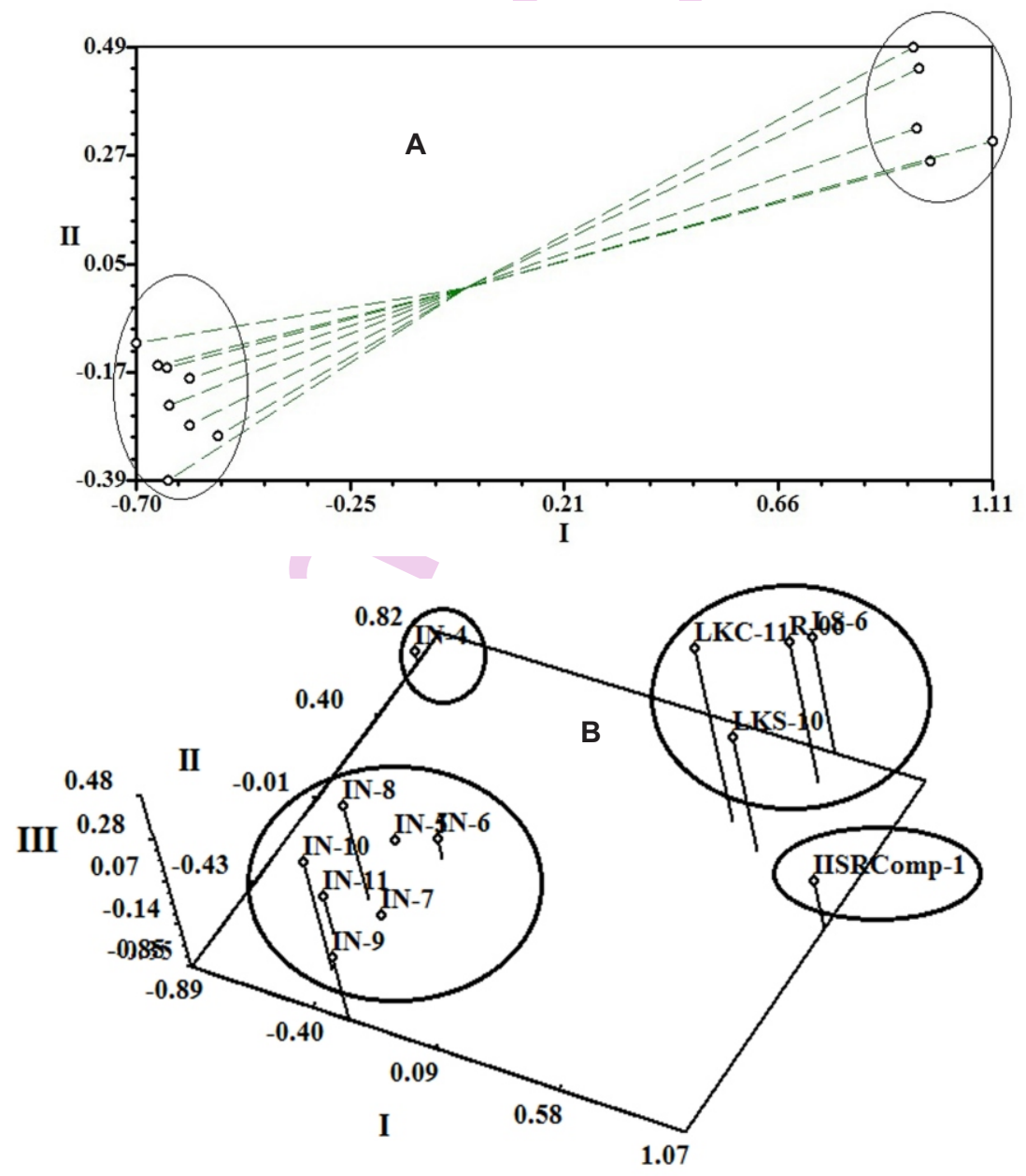

Fig. 3 : Multidimensional plots showing associations among 13 sugar beet genotypes. The scale shows various coordinate levels, A- 2D plot and B-3D plot 


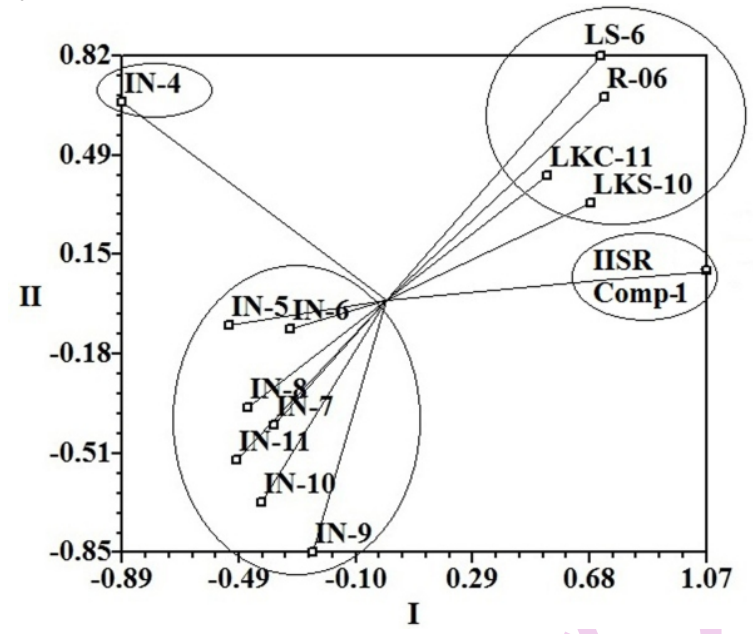

Fig. 4 : The scatter plot of first and second principal component analysis on 13 sugar beet genotypes based on the SSR profiles obtained with fourteen primer combination

Table 2 : Simple matching (SM) similarity coefficient analysis of sugar beet genotypes

\begin{tabular}{|c|c|c|c|c|c|c|c|c|c|c|c|c|c|}
\hline Genotype & & & & SM S & arity coe & icient & & & & & & & \\
\hline Genotype & IN-4 & IN-5 & IN-6 & IN-7 & IN-8 & IN-9 & IN-10 & IN-11 & R-06 & LS-6 & $\begin{array}{l}\text { LKC- } \\
11\end{array}$ & $\begin{array}{l}\text { LKS- } \\
10\end{array}$ & $\begin{array}{l}\text { IISR } \\
\text { Comp-1 }\end{array}$ \\
\hline IN-4 & 1.00 & & & & & & & & & & & & \\
\hline IN-5 & 0.74 & 1.00 & & & & & & & & & & & \\
\hline IN-6 & 0.66 & 0.83 & 1.00 & & & & & & & & & & \\
\hline IN-7 & 0.67 & 0.84 & 0.78 & 1.00 & & & & & & & & & \\
\hline IN-8 & 0.65 & 0.82 & 0.78 & 0.82 & 1.00 & & & & & & & & \\
\hline IN-9 & 0.57 & 0.74 & 0.70 & 0.81 & 0.81 & 1.00 & & & & & & & \\
\hline IN-10 & 0.64 & 0.74 & 0.77 & 0.81 & 0.85 & 0.84 & 1.00 & & & & & & \\
\hline IN-11 & 0.68 & 0.81 & 0.77 & 0.83 & 0.81 & 0.80 & 0.82 & 1.00 & & & & & \\
\hline R-06 & 0.59 & 0.58 & 0.55 & 0.58 & 0.58 & 0.52 & 0.55 & 0.57 & 1.00 & & & & \\
\hline LS-6 & 0.61 & 0.56 & 0.52 & 0.53 & 0.53 & 0.48 & 0.50 & 0.52 & 0.89 & 1.00 & & & \\
\hline LKC-11 & 0.63 & 0.59 & 0.58 & 0.59 & 0.57 & 0.53 & 0.56 & 0.58 & 0.78 & 0.81 & 1.00 & & \\
\hline LKS-10 & 0.51 & 0.55 & 0.51 & 0.52 & 0.50 & 0.47 & 0.49 & 0.53 & 0.72 & 0.76 & 0.80 & 1.00 & \\
\hline IISRComp-1 & 0.51 & 0.57 & 0.53 & 0.57 & 0.52 & 0.53 & 0.51 & 0.56 & 0.72 & 0.76 & 0.75 & 0.77 & 1.00 \\
\hline
\end{tabular}

coefficient analysis (Table 2). The mean coefficient was 0.28 which suggested that these sugar beet genotypes were quite diverse. Srivastava et al. (2007) studied genetic diversity of four populations of sugar beet (B. vulgaris $L$.) using RAPD and ISSR markers and obtained a vast range of genetic similarity (GS) coefficients (RAPD-GS from 0.10 to 0.74 and ISSR-GS from 0.12 to 0.86 ). They proved the ability of DNA based markers to detect high degree of polymorphism among these populations and also the possibility of screening a higher number of anonymous loci in sugar beet to enable the selection of the best parents in order to obtain new genetic combinations. Viard et al. (2002) also emphasized that the genetic diversity estimates between and within genotypes depend not only on the markers chosen for the particular study, but also on the choice of the genotypes analysed. Molecular diversity in these sugar beet genotypes became apparently more clear through the dendrogram (Fig. 2) generated by UPGMA based cluster analysis performed on the similarity matrix. Two taxonomical groups were clearly resolved. The first taxonomical group consisted of eight genotypes viz. IN-4, IN-5, IN6 , IN-7, IN-8, IN-9, IN-10 and IN-11, and the other group clubbed the remaining genotypes. There were five clusters having one, four, three, three and two genotypes each. Three clusters were present in first taxonomical group and two in second taxonomical group. The goodness-of-fit of dendrogram to original genetic similarity matrix was calculated by computing the cophenetic value (rcoph) using COPH (cophenetic) and MXCOMP (matrix comparison) modules. The 2-way Mantel's test (Mantel, 1967) for the correlations between these similarity and cophenetic matrices gave a very high cophenetic correlation coefficient $r=0.96077$, suggesting that SSR markers used in the present study gave an 
efficient analysis of genetic relationships among these genotypes.

In order to better understand their relationships and to visualize the hierarchical clusters among the studied genotypes, multidimensional scaling (MDS) was performed in two and three dimensional (2D and 3D) scatter plots (Fig. 3) using the similarity matrix that was estimated for each genotype. The 2D MDS Plot separated the genotypes into two distinct groups with 8 and 5 genotypes each (Fig. 3a). Distribution of genotypes was more clear in three dimensional MDS plot where even the sub clusters were clearly distinguishable (Fig. 3b). Both scatter plots were in general consistence with the UPGMA cluster analysis; albeit the genotype LKS-10 which clubbed with the sub group IV instead of sub group V as visualized in UPGMA based clustering. Principal Component Analysis, based on genetic similarity matrix, was also used to visualize the genetic relationships among these sugar beet genotypes. This multivariate approach was chosen to complement the cluster analysis information, because cluster analysis may sometime be biased towards closely related genotypes, whereas PCA is comparatively more helpful about distances among major groups (Hauser and Crovello, 1982). The PCA scatter plot (Fig. 4) substantiated the distribution of genotypes in sub groups as obtained by MDS analysis and further authenticated the heterotic groups obtained in the current study. Multidimensional Scaling and cluster analysis are also not mutually exclusive. Rather, the two approaches complement each other (Bertan et al., 2007). This has been clearly visualised in the present study where the clustering pattern of UPGMA and, 2D and 3D plots of MDS match each other; the pattern has been further substantiated through PCA. Moreover, the highly significant cophenetic coefficient of $r$ $=0.96$ suggested that the SSR markers used in the present study gave an efficient analysis of genetic relationships among the genotypes. Clustering pattern of tomato genotypes based on SSR markers was supported by 3D PCA plot (Zhou et al., 2015), however, the distribution of cultivated Rye genotypes on a 2D PCA plot did not conform to groupings from ISSR based UPGMA cluster analysis (Patrovi et al., 2016). Microsatellite markers in general are easy to use and highly reproducible; the technique being PCR-based, only low quantities of template DNA are required. Similar range of size of different alleles makes the multiplexing of SSR primers easy and enhances the possibility of their use in automation (Ghislain et al., 2004). Simko et al. (2012) compared three marker-systems viz. DArT, SNP and SSR markers for estimating genotypic diversity and clustering of sugar beet varieties into populations, and found that across different types of analyses, per locus success-rate was highest for SSRs. Thus, microsatellite markers can be used as a potential cost effective method to explore inherent molecular diversity of sugar beet germplasm, as well as to screen a large number of anonymous loci to enable the selection of the best parents in order to obtain new genetic combinations.

\section{Acknowledgment}

The authors are thankful to the Director, ICAR-IISR, Lucknow for allowing us to use the facilities to carry out this work.

\section{References}

Abbasi, Z., A. Arzaniand and M. M. Majidi: Evaluation of genetic diversity of sugar beet (Beta vulgaris L.) crossing parents using agromorphological traits and molecular markers. J. Agr. Sci. Tech., 16, 1397-1411 (2014).

Barzen, E., W. Mechelke, E. Ritter, E. Schulte-Kappert and F. Salamini: An extended map of the sugar beet genome containing RFLP and RAPD loci. Theor. Appl. Genet., 90, 189-193 (1995).

Bertan, I., F. I. F. Carvalho and A. C. Oliveira: Parental selection strategies in plant breeding programs. J. Crop Sci. Biotechnol., 10, 211-222 (2007).

Desplanque, B., P. Boudry, K. Broomberg, P. Saumitou-Laprade, J. Cuguen and H. Van Dijk: Genetic diversity and gene flow between wild, cultivated and weedy forms of Beta vulgaris L. (Chenopodiaceae), assessed by RFLP and microsatellite markers. Theor. Appli. Geneti., 98, 1194-1201 (1999).

Draycott, A. P.: Sugar beet. Blackwell Publishing Ltd. (2006).

Fugate, K. K., D. Fajardo, B. Schlautman, J. P. Ferrareze, M. D. Bolton, L. G. Campbell, E. Wiesman and J. Zalapa: Generation and characterization of a sugar beet transcriptome. The Plant Genome, 7,1-13(2014).

Ghislain, M., D. M. Spooner, F. Rodriguez, F. Villamon, J. Nunez, C. Vasquez, R. Waugh and M. Bonierbale: Selection of highly informative and user-friendly microsatellites (SSRs) for genotyping of cultivated potato. Theor. Appl. Genet., 108, 881-890 (2004).

Grimmer, M. K., S. Trybush, S. Hanley, S. A. Francis, A. Karp and M. J. C. Asher: An anchored linkage map for sugar beet based on AFLP, SNP and RAPD markers and QTL mapping of a new source of resistance to beet necrotic yellow vein virus. Theor. App. Geneti., $114,1151-1160$ (2007).

Hauser, L. A. and T. J. Crovello: Numerical analysis of generic relationships in the lypodieae (Brassicaceae). Systematic Botany, 7, 249-268 (1982).

Jung, C., K. Pillen, L. Frese, S. Fahrand and A.E. Melchinger: Phylogenetic relationships between cultivated and wild species of the genus Beta revealed by DNA "fingerprinting:' Theor. Appl. Genet., 86, 449-457 (1993).

Kalia, R. K., M. Rai, K. Kalia, S. Singh and R. A. K. Dhawan: Microsatellite markers: an overview of the recent progress in plants. Euphytica, 177, 309-334 (2011).

Laurent, V., P. Devaux, T. Thiel, F. Viard, S. Mielordt, P. Touzet and M. C. Quillet: Comparative effectiveness of sugar beet microsatellite markers isolated from genomic libraries and Gen Bank ESTs to map the sugar beet genome. Theor. Appl. Genet., 115, 793-805 (2007).

Mantel, N. A.: The detection of disease clustering and a generalized regression approach. Cancer Res., 27, 209-220 (1967).

Möhring, S., F. Salamini and K. Schneider: Multiplexed, linkage groupspecific SNP marker sets for rapid genetic mapping and fingerprinting of sugar beet (Beta vulgaris L.). Mol. Breed., 14, 475-488 (2005).

McGrath, J. M., D. Trebbi, A. Fenwick, L. Panella, B. Schulz, V. Laurent, S. Barnes and S. Murray: An open-source first-generation molecular genetic map from a sugar beet $x$ table beet cross and its extension to physical mapping. Plant Gen., 1, S27-S44 (2007).

Mörchen, M., J. Cuguen, G. Michaelis, C. Hänni and P. SaumitouLaprade: Abundance and length polymorphism of microsatellite repeats in Beta vulgaris L. Theor. Appl. Genet., 9, 326-333 (1996).

Partovi, N., M. Ebrahimi and Z. Alemi: Evaluation of genetic variation in rye germplasm using ISSR markers. Electronic J. Biol., 12, 77-82 (2016). 
Pathak, A. D., R. Kapur, S. Solomon, R. Kumar, S. Srivastava and P. R. Singh: Sugar Beet : A historical perspective in Indian context. Sugar Tech., 16,125-132 (2014).

Rae, S. J., C. Aldam, I. Dominguez, M. Hoebrechts, S. R. Barnes and K. J. Edwards: Development and incorporation of microsatellite markers into the linkage map of sugar beet (Beta vulgaris spp.). Theor. Appl. Genet., 100, 1240-1248 (2000).

Richards, C. M., M. Brownson, S. E. Mitchell, S. Kresovich and L. Panella: Polymorphic microsatellite markers for inferring diversity in wild and domesticated sugar beet (Beta vulgaris). Mol. Ecol. Notes, 4, 243-245 (2004).

Rohlf, F. J.: NTSYSpc Numerical Taxonomy and Multivariate Analysis. System Version 2.11 Exeter Software, New York (2000).

Schneider, K., D. Kulosa, T.R. Soerensen, S. Moehring, M. Heine, G. Durstewitz, A. Polley, E. Weber, J. Lein, U. Hohmann, E. Tahiro, B. Weisshaar, B. Schulz, G. Koch, C. Jung and M. Ganal: Analysis of DNA polymorphisms in sugar beet (Beta vulgaris L.) and development of an SNP-based map of expressed genes. Theor. Appl. Genet., 115, 601-615 (2007)

Schondelmaier, J., G. Steinrücken and C. Jung: Integration of AFLP markers into a linkage map of sugar beet (Beta vulgaris $L$.). Plant Breed., 115, 231-237 (1996).

Simko, I., I. Eujayl and T. J. L. van Hintum: Empirical evaluation of DArT, SNP and SSR marker-systems for genotyping, clustering, and assigning sugar beet hybrid varieties into populations. Plant Sci. 184, 54-62 (2012).

Smulders, M., G. Esselink, I. Everaert, J. De Riek and B. Vosman: Characterisation of sugar beet (Beta vulgaris L. ssp. vulgaris) varieties using microsatellite markers. BMC Genet.,11, 41-52 (2010).

Sneath, P. H. A. and R. R. Sokal: Numerical Taxonomy. Freeman. San Francisco, p. 573(1973).

Srivastava, S., P. S. Gupta, V. K. Saxena and H. M. Srivastava: Genetic diversity analysis in sugar beet (Beta vulgaris $L$.) using isozymes, RAPD and ISSR markers. Cytologia, 72, 265-274 (2007).

Srivastava, S. and P. S. Gupta: Microprep protocol for DNA isolation from sugarcane. Ind. J. Sugarcane Technol., 16, 88-90 (2001).

Viard, F., J. Bernard and B. Desplanque: Crop-weed interactions in the Beta vulgaris complex at a local scale: Allelic diversity and gene flow within sugar beet fields. Theor. Appl. Genet., 104, 688-697 (2002).

Weiland, J. J. and M. H. Yu: A cleaved amplified polymorphic sequence (CAPS) marker associated with root-knot nematode resistance in sugarbeet. Crop Sci., 43, 1814-1818 (2003).

Zhou, R., Z. Wu, X. Cao and F.L. Jiang: Genetic diversity of cultivated and wild tomatoes revealed by morphological traits and SSR markers. Genet. Mol. Res., 14, 13868-13879 (2015). 